\title{
The Right to be Forgotten and the Media
}

\author{
MAJA OvČAK KOS
}

\begin{abstract}
The right to be forgotten is not the right to a "perfect" past, but provides some control over one's personal information on the Internet under certain conditions. Its content and scope cannot be defined precisely, but its essence is undoubtedly the individual's entitlement, based primarily on the right to respect one's private and family life, to request erasure of personal data or information on the basis of which an individual can be identified against any controller. The right to be forgotten is a legal concept still at the beginning of its development, and case law will have to play a decisive role in shaping its content. An important limitation on the right to be forgotten is the passive aspect of the right to freedom of expression. Therefore, in the case of media contributions, the restriction on the exercise of the right to be forgotten is justified by particularly strong, substantiated reasons. In resolving the conflict between the right to be forgotten and the freedom of media expression, it is necessary to proceed from criteria which, regarding the conflict between Articles 8 and 10 of the ECHR were set up by the ECtHR.
\end{abstract}

Keywords: - the right to be forgotten - freedom of expression and information $\bullet$ case law $\bullet$ conflict $\bullet$ media $\bullet$ media online archives $\bullet$ internet search engines $\bullet$ GDPR $\bullet$

Correspondence AdDress: Maja Ovčak Kos, PhD, Assistant Professor, International School of Social and Business Studies, Celje, Slovenia, e-mail: maja.ovcak.kos@mfdps.si. 
Today's society is heavily dependent on modern technologies. The Internet has become an important element of our daily lives, as it is used in many activities, such as shopping, banking, studying, researching, storing data, etc. With the emergence of the Internet, our lives have changed dramatically, as technical and institutional barriers for disseminating and receiving information were removed and foundations for various information society services were laid. ${ }^{1}$ The Internet has evolved into a large-scale worldwide database that can be accessed anywhere and browsed. Each of our activities leaves traces in the digital world, with possible significant consequences for our lives (Spahiu, 2015: 1). People today often create their (original) opinion on individuals, business partners, employers, attorneys, etc. primarily on the basis of information available on the Internet. Data show that more and more employers are looking for job seekers' information, mainly through the Internet, and create an image based on it before they even get to meet them in person. ${ }^{2}$ We trust the Internet with various personal information, generally unaware of the importance and consequences of such conduct, even to the extent that we would not want to be publicly available. The Internet enables permanent recording of personal data and their rapid and easy reproduction with no territorial restrictions. If, from the beginning of humanity, forgetting was the rule and memory the exception in human nature, today we can conclude the opposite - the Internet makes it impossible for us to forget, so forgetting is increasingly becoming an exception (Mayer-Schönberger, 2009: 1).

In May 2014, The European Court of Justice (hereinafter: CJEU), in case of Google Spain SL v AEPD and M. González ${ }^{3}$ ruled that there exists the right to be forgotten that gives individuals, in relation to search engines, entitlement to erase Internet search results (URL) that are inappropriate, inadequate, no longer relevant or excessive for these purposes and time elapsed. The right to be forgotten is an emerging legal concept that allows individuals to exercise some control over their online personal information. Google practice demonstrates that search results are usually erased in the following cases: when it comes to sensitive personal information, such as personal contacts, addresses, health information, data concerning the ethical, racial or religious affiliation of individuals, in case of minor

\footnotetext{
${ }^{1}$ Cf. Opinion of Advocate General Niil Jääskinen in Case C-131/12, Google Spain Sl, Google Inc. v Agencia Española de Proteccion de Datos (AEPD) and Mario Costeja González, ECLI: EU: C: 2014: 317.

${ }^{2}$ Cf. Copper, 2011: 1.

${ }^{3}$ Case C-131/12, Google Spain Sl, Google Inc. v Agencia Española de Proteccion de Datos (AEPD) and Mario Costeja González, ECLI: EU: C: 2014: 317 (Google Spain).
} 
offences, particular with adolescents involved, in cases of criminal offences when, in criminal proceedings, individuals are acquitted or criminal convictions erased from criminal records (Xue, Magno, Cunha, Almeida, Ross, 2016: 391). In the last year, however, a significant increase in the number of requests for erasure made by individuals directly against online media publishers for erasure of some legitimately published articles available in online media archives containing the personal data of the enforcer, can be observed. Although it should be expected that the majority of these requests would relate to articles containing personal information on criminal acts or offences having already been rehabilitated for the most part, this cannot be agreed with. It can in fact be established that the range of journalistic articles, erasure of which has been requested, is quite diverse, e.g. from media coverage of candidates for government positions, personal connections between influential economists, business performance of individual entrepreneurs, a successful story of a young unemployed graduate getting employed, to erasure of a wrong phone number from a small ad in a newspaper, etc.

Requests for erasure of lawfully ${ }^{4}$ published newspaper articles containing real personal information of individuals, or for anonymisation of articles directed against online media publishers place the right to be forgotten in a broader context, especially in a conflict with freedom of journalistic expression and the right of the public to be informed. The purpose of the paper is to find out, also by taking into account the comparative legal argument and the case law of the European Court of Human Rights (hereinafter: ECtHR), what is actually the content of the aforementioned conflicts of rights, in particular the right to be forgotten, and what criteria are relevant in their value-weighing and finding the right balance. In the second chapter, the paper will deal with the issues of the legal basis, subject matter and scope of protection of the right to be forgotten, as well as with peculiarities of its enforcement in relation to online media or online media archives. The main research aspect of the third chapter is to identify the constitutionally protected nucleus of freedom of expression, to protect the right to be forgotten in the ECtHR practice and in the case law of European countries, as well as to identify the criteria relevant for assessing the conflict between the right to be forgotten and freedom of expression. In chapter four, conclusions are given.

\footnotetext{
${ }^{4}$ It can, of course, be considered otherwise if the article contains false, untrue or fabricated information or personal information.
} 


\section{Legal basis, subject matter and extent of protection of the right to be forgotten}

\subsection{Google Spain SL v AEPD and M. González}

Until the adoption of the General Data Protection Regulation ${ }^{5}$ (hereinafter: General Regulation), the CJEU judgment in the Google Spain case constituted the legal basis for the right to be forgotten on the Internet. The CJEU, in that case, interpreted a nearly twenty-year-old European law on the protection of personal data ${ }^{6}$ in the light of new technological capabilities, above all considering the importance and reach of the Internet as a new mass digital medium, which differs significantly from media in the analogue environment, especially in the way of communication and information. In time of adopting the Directive 95/46/EC, the world wide web was only just becoming reality and search engines were still in their infancy, which made it impossible for the EU legislature to predict the development of the Internet into such a large database as it is today. ${ }^{7}$

The facts of the case were as follows. In early 1998, a high-circulation newspaper in Spain published in its printed edition two announcements concerning a real-estate auction connected with enforcement proceedings prompted by social security debts. Mario C. González, a Spanish national to whom personal data related, was listed as the owner. At a later date an electronic version of the newspaper was made available online by its publisher. González contacted the newspaper's publisher in November 2009 , claiming that a link to the newspaper's real-estate auction listing page would appear on Google's search engine when entering his name and surname. He argued that the enforcement proceedings due to his non-payment of social security contributions were completed and resolved many years ago and are now pointless. The publisher replied that his data would not be erased, given that the publication was effected by order of the Ministry of Labour and Social Affairs. In 2010, González demanded from Google Spain that search results, should his name

\footnotetext{
${ }^{5}$ Regulation (EU) 2016/679 of the European Parliament and of the Council from 27. 4. 2016 on the protection of individuals with regard to the processing of personal data and on the free movement of such data and repealing of the Directive 95/46/EC (OJ EU L 119, 4. 5. 2016, p. 1).

${ }^{6}$ Directive 95/46/EC of the European Parliament and of the Council of 24 October 1995 on the protection of individuals with the processing of personal data and the free movement of such data (OJ EC L 281, 23. 11. 1995, p. 31; hereinafter: Directive 95/46/EC).

${ }^{7}$ Cf. Opinion of Advocate General Niil Jääskinen delivered on 25. 6. 2013 in the case Google Spain, point 78.
} 
and surname be typed into Google search engine, do not include links to the newspaper. ${ }^{8}$

The CJEU held that ${ }^{9}$ an individual has the right that personally relevant information, by enforcing his claim, is no longer linked to his name through a list of links that appear as a result of a search engine search. This applies not only in cases of inaccurate data, but also when personal data are inappropriate, inadequate, not updated or excessive in relation to the purpose of processing and the time elapsed, ${ }^{10}$ and even if individual's personal information is not previously or concurrently erased from the source web pages, or if their publication on those pages is in itself lawful. ${ }^{11}$ The presumption of the right to be forgotten is not the damage suffered by the beneficiary. ${ }^{12}$ It can also be noted that ${ }^{13}$ the passage of time is an important element of the right to be forgotten, ${ }^{14}$ as information should be forgotten after a certain period of time and the individual's "imperfect" past should be erased. ${ }^{15}$ The CJEU decision was justified (also) on the basis of Article 7 (right to respect for privacy) and Article 8 (right to protection of personal data) of the Charter of Fundamental Rights of the European Union (hereinafter: Charter), ${ }^{16}$ which constitute the source of the right to be forgotten and, according to CJEU, as a rule, give it an advantage over the public interest in accessing information. ${ }^{17}$ The exemption would apply, in the CJEU view, in case of specific reasons, such as the role of a person in public life, where interference with one's fundamental rights would be justified by the overriding interest of the public to have access to the information in question through that inclusion. ${ }^{18}$

Frantziou's $(2016: 766,769)$ on the subject of the value weighing, followed by the CJEU, rightly points out that the public has not only an interest in access to information but a right guaranteed in Article 11 of the Charter. From the perspective of our research, it should be noted that in resolving the conflict between freedom of

\footnotetext{
${ }^{8}$ See points 19 and 20 of Opinion of Advocate General Niil Jääskinen delivered on 25 6. 2013 in the case Google Spain and points 14 and 15 of the judgment in the Google Spain case.

${ }^{9}$ The decision has been heavily criticised in the professional and general public. See Zittrain, 2014: 761-777; Iglezakis, 2014: 1-16 et al.

${ }^{10} \mathrm{Cf}$. point 92 of the CJEU judgment Google Spain.

${ }^{11}$ Cf. point 88 of the CJEU judgment Google Spain.

${ }^{12}$ Cf. point 96 of the CJEU judgment Google Spain.

${ }^{13}$ Some authors believe that this is not a right, but a value or interest (Koops, 2011: 230 and 232).

${ }^{14}$ See points 89-96 of the CJEU judgment Google Spain.

${ }^{15}$ Details of other aspects of the CJEU judgment in the case Google Spain see Frantziou, 2014: 761-777.

${ }^{16}$ OJ EU C 83, 30. 3. 2010, p. 391.

${ }^{17}$ See point 99 of the CJEU judgment Google Spain.

${ }^{18}$ Ibid.
} 
expression and the right to privacy, the CJEU did not clearly define the scope of the right to be forgotten nor clarify the relationship with European Convention for the Protection of Human Rights and Fundamental Freedoms (hereinafter: ECHR) ${ }^{19}$ and the practices of the ECtHR, although these are also convention rights to which all EU Member States as signatories to the ECHR are bound. The answer to the question of the importance of the ECtHR practice in dealing with requests for being forgotten is not given by the CJEU. Nor did the court specify the scope of the provisions of Articles 7 and 8 of the Charter. It also remains unclear when it comes to data that is inappropriate, inaccurate or no longer relevant or excessive (Cf. Kulk, Zuiderveen Borgesius, 2014: 6), as more specific criteria were not given in the CJEU judgment. Based on the analysis of the Google Spain judgment it can thus be concluded that in each case the balance between the right to privacy and freedom of expression must be weighed. In view of the fact that the CJEU court in the Google Spain case did not give any concrete and precise criteria, in the weighing of the significance of both the ECHR and the Charter values, it should be kept in mind that the balance established by the CJEU cannot be also applied to cases of online media or original online posts, since the criteria in my opinion cannot be the same. There is a significant difference between web media and search engines, as search engines make information accessibility easier for all internet users who search for information about a particular person and make a significant contribution to the dissemination of that information, compared to online media. ${ }^{20}$ In addition, Directive 95/46/EC has already provided the media with a legal basis for the so-called journalistic exception. ${ }^{21}$

After the Google Spain judgment was delivered, the Article 29 working group, ${ }^{22}$ in order to ensure greater legal predictability and clarity, adopted the optional guidelines for the implementation of the CJEU judgment. It identified more specific criteria that could be relevant in the decision-making process of national data protection authorities, namely the status of the data subject, the nature of the information, the possible implications of that information for the individual and the circumstances of the publication.

\footnotetext{
${ }^{19}$ Official Gazette of the RS-MP, No. 7-41/1994 and 33/1994.

${ }^{20} \mathrm{Cf}$. point 87 of the CJEU judgment Google Spain.

${ }^{21}$ See Article 9 of the Directive 95/46/EC.

${ }^{22}$ See Guidelines on the implementation of the Court of Justice of the European Union judgment on "Google Spain and inc v. Agencia Española de Protección de Datos (AEPD) and Mario Costeja González" C-131/121, pp. 13-20.
} 


\subsection{General Data Protection Regulation}

\subsubsection{The legal basis of the right to be forgotten}

The General Regulation, which entered into force in May 2018, regulates, in Article 17, the right of erasure (the right to be forgotten). ${ }^{23}$ This applies to all personal data or information that can be used to identify a particular individual and can be leveraged against any controller, whether it is a source web site or an Internet search engine. ${ }^{24}$ It is guaranteed only to natural persons. ${ }^{25}$ It is reasonable to agree with the reasoning of Kreča, that sole proprietors should be considered as beneficiaries as well (Kreča, 2017: 24). Recital 65 to the General Regulation states that this right is particularly important when an individual data subject has given consent as a child and was not fully aware of the risks involved in processing, and later wishes to remove such personal information, especially from the Internet.

The provision of Article 17(1) of the General Regulation gives an individual the right $^{26}$ that, at his request, the controller must, without undue delay, erase related personal data where one of the six reasons stated exist, ${ }^{27}$ namely, if the purpose of the processing is dropped, if the processing was unlawful (the latter relates mainly to inaccurate data), when one withdraws one's consent, objects to the processing of whether there is a specific case of a direct provision of information technology services to a child. According to the provision of Article 17(2) of the General Regulation, the decisive condition for erasure is that the controller published the data publicly, but it does not have to be an online publication.

In view of our examination, Article 17(3) of the General Regulation, which provides for exceptions to the exercise of the right to be forgotten, is important. In accordance with Article 17(3)(a) of the General Regulation, one of them is also to guarantee the right to freedom of expression and information. It should be noted that this exception does not specify a specific concretisation, orientations or specific criteria for assessment, so in my view the conflict between freedom of expression and the right to be forgotten must be based on criteria developed by the ECtHR (which will be

\footnotetext{
${ }^{23}$ For a terminological dilemma, the right to be forgotten or the right to be erased in more detail, see Kreča, 2017: 22-26.

${ }^{24}$ Cf. Case C-101/01, Criminal proceedings against Bodil Lindqvist, ECLI: EU: C: 2003: 596.

${ }^{25}$ See Article 1(1) of the General Regulation.

${ }^{26}$ To that extent, the first paragraph of Article 17 of the General Regulation does not constitute a significant novelty with regard to Article 12 of Directive 95/46.

${ }^{27}$ See Article 17(1) of the General Regulation.
} 
explained in more detail below) in resolving the conflict between freedom of expression and the right to be forgotten.

The question arises as to whether the right to be forgotten, as provided for in Article 17 of the General Regulation, is the same right as derived from the practice of the CJEU. European case law has not yet provided an explicit answer to this question. In my opinion, there is no doubt that the two rights pursue the same objective - to enable the individual to erase the imperfect past on the Internet, but it should be emphasised that the scope of the provision of Article 17 of the General Regulation on the right to be forgotten is considerably broader than apparent from the Google Spain CJEU case, as it is not restricted to search engines. ${ }^{28}$ It also covers all personal information, not only the name and surname, and provides protection not only in cases of loss of interest in past, irrelevant information, but also in other situations, such as unlawful processing or withdrawal of consent (Kreča, 2017: 37). ${ }^{29}$

There are numerous interpretations of the range and scope of the right to be forgotten in the literature. Some theorists, e.g. Mayer-Schöberger, see the fundamental emphasis of the right in the fact that personal data must be erased after a certain period of time, especially the old and irrelevant ones (Koops, 2011: 14). Others (e.g., Blanchette and Johnson, Werro etc.) are based on the theory of a new beginning, with some emphasising the position of the individual and his freedom of expression without regret, and others the social, societal aspect that negative outdated information that is no longer relevant to the individual's current life should not be used against one (Koops, 2011: 22 and 26).

Therefore, it can be concluded that, given the fact that (case) law regarding the application of Article 17 of the General Regulation is almost non-existent and that in literature on the range and scope of the right to be forgotten opinions vary greatly, the content of the right to be forgotten or to erasure cannot be defined precisely. Undoubtedly, its essential core is the individual's entitlement, based primarily on the right to privacy, to request the erasure of personal data or information on the basis of which one can be identified against any controller, whether it is a source website or an Internet search engine. The right to be forgotten is therefore a legal concept still at the beginning of its development, and case law will have to play a decisive role in shaping its content.

\footnotetext{
${ }^{28}$ Cf. Article 17(1) and (2) of the General Regulation.

${ }^{29}$ For more, see Montelero, 2013: 8-10.
} 


\subsubsection{Exercise of the right to be forgotten}

An individual submits a request for erasure directly against the controller of ${ }^{30}$ personal information, that is, the source web site manager or the internet search engine. It should be emphasised that an individual can make a request simultaneously to all data controllers. In accordance with Article 12 of the General Regulation, the controller must decide upon the request within one month, and the individual is legally protected against the decision via the Information Commissioner (complaint or notification). If the request is denied, the controller must explain and substantiate the reasons and inform the applicant on legal protection against such a decision.

Practice shows that erasure requests represent a significant burden for online media broadcasters, not only in terms of the amount of requests they receive, but also in terms of content complexity. It seems problematic that the weighing between two fundamental human rights, the right to be forgotten and the freedom of expression, which is inherent in judicial decision-making, is primarily left to private individuals as majority managers, who are generally legal laymen (cf. Frantziou, 2014: 770). The fear of arbitrariness rather than equal treatment of comparable cases is compounded by the fact that criteria relevant to the assessment are still rather vague and the case law is rather modest ${ }^{31}$ (almost non-existant in Slovenia). Therefore, as the weighing of fundamental rights is left primarily to private individuals and not to the court, the question of ensuring a comprehensive, uniform and harmonised treatment of claims seems justified. On the other hand, some authors convincingly point out that the public should also have possibility to be legally protected in case of erasure of information or an article, as this interferes with the right to know and to access information. ${ }^{32}$ It should also be noted that in most cases the refusal to erase an article by an online media publisher will not be sufficiently justified only by reference to the exemption referred to in Article 17(3)(a) of the General Regulation, but as a rule it will also be necessary to justify the reasons referred to in Article 17(1) of the General Regulation, particularly that the purpose of processing of personal data has not ceased. ${ }^{33}$

\footnotetext{
${ }^{30}$ The term controller is defined in point 7 of Article 4 of the General Regulation as a natural or legal person, public body, agency or other body which alone or together with others determines the purposes and means of processing.

${ }^{31}$ This is a case-law on the conflict of freedom of expression and the right to be forgotten.

${ }^{32}$ Report: The Advisory Council to Google on the Right to be Forgotten, p. 18.

${ }^{33}$ See Article 17(1)(a) of the General Regulation.
} 


\subsection{The (constitutionally) protected core of the right of freedom of expression}

It was established that the right to be forgotten has its substrate in the provisions of Articles 7 and 8 of the Charter. The question arises whether the right to be forgotten is also protected within the ECHR, which also protects privacy by the provision of Article 8. An important aspect of restriction of the right to be forgotten is the freedom of expression and information, which raises the question of the role of the ECHR in interpreting the EU's fundamental rights as determined in the Charter. Furthermore, what circumstances may be relevant in assessing whether the exercise of one right excessively restricts the exercise of another right. The answer to the latter requires first finding the central essence of the right to freedom of expression.

Freedom of expression and information is a fundamental right protected by Article 11 of the Charter and Article 10 of the ECHR. The Constitution of the Republic of Slovenia ${ }^{34}$ provides it with the provision of Article 39. Regarding the definition of the essential content of this right, it should be emphasised that, in addition to being a direct expression of one's personality in society, freedom of expression is also a fundamental constituent element of a free democratic society. The meaning and role of freedom of expression are therefore multifaceted. ${ }^{35}$ Its function is to protect the freedom to impart information and opinions (the active aspect), as well as the freedom to receive them, i.e. the right to be informed ${ }^{36}$ (passive aspect). ${ }^{37}$ Freedom of the press plays a particularly important role in the right to freedom of expression, helping to establish and shape an impartially informed public. ${ }^{38}$ Freedom of speech, therefore, is of particular importance when it comes to expression within the journalistic profession, since the broad boundaries of press freedom are one of the cornerstones of modern democratic society. This is particularly the case for reporting on topics of general public interest in information. ${ }^{39}$ Only the public, up to date and accurately

\footnotetext{
${ }^{34}$ Official Gazette of the RS, No. 33/91-I , 42/97 - UZS68, 66/00 - UZ80, 24/03 - UZ3a, 47, 68, 69/04 UZ14, 69/04 - UZ43, 69/04 - UZ50, 68/06 - UZ121,140,143, 47/13 - UZ148, 47/13 - UZ90, 97, 99 and 75/16 - UZ70a.

${ }^{35}$ See decisions: ECLI: SI: USRS: 2009:Up.1391.07, ECLI: SI: USRS: 2009: Up.2940.07, ECLI: SI: USRS: 2016: Up.407.14, ECLI: SI: VSRS: 2018: III.IPS.71.2016 et al.

${ }^{36}$ Cf. Times Newspaper Ltd. against the United Kingdom, no. 3002/03 and 23676/03 from 10. 3. 2009.

${ }^{37}$ See decisions: SI: USRS: 2009:Up.1391.07, ECLI: SI: USRS: 2009:Up.2940.07, ECLI: SI: USRS: 2016: Up.407.14, ECLI: SI: VSRS: 2018: III.IPS.71.2016 et al.

${ }^{38}$ See decision: SI: USRS: 1994: U.I.172.94.

${ }^{39}$ See decision: SI: USRS: 2004: Up.91.02.
} 
informed, can successfully participate in the management of matters of general interest. $^{40}$

Similar views are drawn from ECtHR case law. According to the ECtHR, it is the duty of the media to provide information in all matters concerning the public in a manner consistent with its responsibilities and duties. On the other hand, the public has the right to receive this information, otherwise the press would not be able to perform its important role as a guard dog. ${ }^{41}$ Freedom of speech, as one of the cornerstones of a democratic society, therefore extends to information that may be offensive, shocking or disturbing. Restrictions on freedom of expression must be strict and convincing. ${ }^{42}$ It should be emphasised that the practice of the ECtHR does not imply the supremacy of freedom of expression to other convention rights. As is the case with other rights, it may be limited by the right of another or for the reasons stated in the second paragraph of Article 10 of the ECHR. However, in the ECtHR's view, it is precisely because of its earlier underlined importance for functioning of a democratic society that restrictions must be narrow. ${ }^{43}$

\subsection{The EU's right to be forgotten and the practice of the ECtHR}

Based on an analysis of the ECtHR case law, it can be concluded that in several cases the court has assessed the protection of personal data in the online environment.

Therefore in cases Editorial Board of Pravoye Labor and Shtekel v. Ukraine ${ }^{44}$ and Times Newspaper Ltdf $v$. The United Kingdom, ${ }^{45}$ it underlined the important role of the Internet in the exercise of freedom of expression under Article 10 of the ECHR, but emphasised its incomparability with the print media. Online media archives, as the ECtHR has pointed out in the case Wegrzynowski and Smolczewski v. Poland, ${ }^{46}$ contribute significantly to access to information and are an important source of information. In this case, two lawyers asked the online media to remove a newspaper article, which was also available in the online media archive. The controversial newspaper article contained allegations that they should be involved in suspicious business deals with Polish politicians and that they had acquired significant public

\footnotetext{
${ }^{40}$ See decision: SI: VSLJ: 2009: I.Cp.3167.2009.

${ }^{41}$ See decision: SI: USRS: 2009: Up.1391.07, point 12 and the ECtHR practice cited therein.

42 Ibid.

${ }^{43}$ For more details, see Bychawska-Siniarska, 2017: 10-20.

${ }^{44}$ No. 33014/05, judgment from 5. 5. 2011.

${ }^{45}$ No. 3002/93 and 23676/03, judgment from 10. 3. 2009.

${ }^{46}$ No. 33846/07, judgment from 16. 7. 2013.
} 
funds benefits as liquidators of state-owned companies. Although the ECtHR did not explicitly recognise the right to be forgotten in the provision of Article 8 of the ECHR, some theorists argue to the contrary that the ECtHR has established its own version of the right to be forgotten by the decision in question (Frantziou, 2014: 772). Public interest in accessing information originating from online media archives is protected by Article 10 of the ECHR. Restriction of freedom of expression can only be justified by particularly strong and substantiated reasons (Frantziou, 2014: op. 57). ${ }^{47}$ The ECtHR also raised the concern that deleting articles from online media archives could rewrite history. ${ }^{48}$ One of the functions of the media is to keep the past reports accessible in public archives. ${ }^{49}$

In June 2018, the ECtHR, in the case M. L. and W. W. v. Germany ${ }^{50}$ held that Germany had correctly rejected the request to erase several articles by two individuals, thus properly balancing the right of access to information in relation to the right to respect for private life. Both appellants, half-brothers, were in 1991 convicted to life in prison for murdering a well-known German actor. In 2008, they were conditionally released from prison. In a lawsuit against a German radio station and two newspapers they claimed the removal of all articles and radio interviews relating to the 1991 murder, which referred to them by their full name, from the online media archives and anonymisation of all their related personal information, published on media websites. In the provision of Article 8 of the ECHR, the ECtHR explicitly recognised the basis for the right to be forgotten and, on the other hand, highlighted the public interest in being informed of the complainant's negative action. The role of the media in shaping of public opinion is also realised through access to older (archival) news. Anonymising articles is undoubtedly a less restrictive measure, compared to its erasure from an online archive, in terms of restricting media freedom, but the way in which a subject is reported is a matter of journalistic freedom. Ordering the removal of identifying elements from the event reports could prove to be a deterrent to media freedom of expression. Thus, the ECtHR recognised an important element of journalistic work in individualised information of a journalistic contribution (e.g. name and surname of an individual), especially when reporting on criminal proceedings, and there was a strong public interest in this information. The fact that the complainants were not unknown to the public prior to the request for

\footnotetext{
${ }^{47}$ Ibid., point 57. See also the judgment in the case Timpul Info-Magazine and Anghel v Moldova, no. 42864/05 from 27. 11. 2007, point 31 .

${ }^{48}$ This aspect in the Google Spain case was not subject to review.

${ }^{49}$ No. 33846/07, judgment from 16. 7. 2013, points 59, 65 and 66.

${ }^{50}$ No. 60798/10 and 65599/10, judgment from 28. 6. 2018.
} 
anonymisation was emphasised as important circumstances in the value weighing, as they repeatedly contacted the media during the criminal proceedings, that access to some of the content in question was conditional on a single payment or a subscription, and that the complainant have not contacted search engine managers to make it difficult for public to track the content in question.

\subsection{The right to be forgotten in the jurisprudence of European countries}

In April 2016, the Belgian Supreme Court assessed the conflict between the right to privacy and freedom of expression of the media. The claimant, a Belgian doctor, has filed a lawsuit against a Belgian newspaper for including an already published, old article in a new digital archive. ${ }^{51}$ It contained personal information of a doctor, convicted of causing a car accident many years ago, with the conviction already erased. The aforementioned doctor asked the media to anonymise the article, which was rejected by the media, so he demanded the exercise of the right to privacy in court. The Court of Appeal ruled in favor of the plaintiff, which was also upheld by the Supreme Court. In assessing the conflict between the right to privacy and the freedom of the press, the courts considered the following to be decisive: that there was no specific reason for republishing the article, that the content of the article had no historical value, that a certain time had to elapse between the first and the second publication (20 years in this specific case), that the plaintiff is not a public figure, that the plaintiff's sentence has already been executed and erased and that the plaintiff has been rehabilitated by criminal law (van Calster, 2017: 3, 4).

In 2015, the Spanish Supreme Court faced a similar problem. ${ }^{52}$ The actual background to the dispute was as follows. In 1985, a reputable print medium published an article about two individuals convicted of drug trafficking. In 2009, when their criminal conviction had already been erased from the criminal record, custodial sentence served and convicted individuals already criminally rehabilitated, the article was still available in the online media. The convicted individuals asked the media to remove information about their conviction from digital archives and to take steps to prevent their story from appearing in web search results. The Supreme Court resolved the conflict between the freedom of expression and the protection of

\footnotetext{
${ }^{51}$ Supreme Court of Belgium, 29. 4. 2016, C.15.0052.F, http://jure.juridat.just.fgov.be/view_decision.html?justel=N-20160429-2, visited 4. 12. 2018.

52 Case 545/2015 from 15. 10. 2015, available at http://www.phaedra-project.eu/wpcontent/uploads/PHAEDRA-II_SP_AEPD_Right-to-be-forgotten_UJI_November2015.pdf, last visited 30.11. 2018.
} 
personal data or privacy in favour of the former and dismissed the claim. It emphasised that the right to be forgotten does not guarantee retrospective censorship of information that was correct. The scope of the right to be forgotten is limited to search engines and cannot be extended to digital media archives. Otherwise, this would be excessive and would also inadmissibly restrict freedom of the press.

Echoed and heavily criticised in the legal literature (Scorza 2016: 1; Matthews 2016: 1) was the decision of the Italian Supreme Court of Cassation no. 13161 from June 24, 2016 (Scorza 2016: 1; Matthews 2016: 1), which, on the basis of the protection of the right to be forgotten, upheld the lower courts' assessment of the time limit for the publication of online newspaper articles. The restaurant owners have called for the withdrawal of a journalist's contribution, available in the online archive of a local online media, which dealt with the court case in which they were involved. The plaintiffs did not substantiate the claim for withdrawal of the article by the improbability of the facts written in the article, nor by the lack of public interest, but by the timing of the published information. The Supreme Court, which affirmed the plaintiffs, highlighted the time elapsed between the first publication of the paper and the request for its withdrawal (which was two and a half years in the present case) as a key aspect in assessing the conflict between the right to privacy and freedom of expression. The court based its decision on the fact that given the widespread availability of news published online, the relevant time period (i.e. two and a half years) should be considered as an appropriate time period for the public interest in the information to be sufficiently fulfilled, which gives priority to the right to privacy of the individual. Thus, without any specific legal basis, the court charged the public right to be informed with the shelf "life".

On the basis of the above, it can be concluded that in European case law, which is very narrow in most EU Member States, there is no uniform approach to understanding and defining the scope and range of the right to be forgotten, especially in relation to freedom of media expression. This is reflected in the contradictory decisions of the highest national courts of individual countries in cases with comparable factual and legal circumstances. The criteria for conflict assessment vary and the ECtHR practice cannot be recognised as a decisive starting point. The Italian practice particularly significantly deviates from the standards applied in the ECtHRs practice of assessing the respective conflict of rights. 


\subsection{Conclusions on the conflict between the right to be forgotten and freedom of expression}

The right to be forgotten is not only a legal institute of EU law, but also a convention value, which has its basis in protecting the right to respect for private and family life under Article 8 of the ECHR. Its important limitation is, in particular, the passive aspect of the right to freedom of expression and information (which also protects the public interest in accessing information originating from online media archives). The role of the media in shaping public opinion is also realised through access to older (archival) news. Therefore, in the case of the media (whose position is different from that of the search engine according to the ECtHR), limiting the exercise of this right is justified only by particularly strong and substantiated reasons. In particular, the following aspects, which require particular attention when weighed, need to be taken into consideration, namely that an order to erase an article containing personal information from a source website (whose publication was lawful) may be a form of censorship or allows for manipulation of (correct and true) information, so that changing the article can rewrite history, and that ordering the removal of identifying elements from articles as well as deleting them may prove to have a deterrent effect on media freedom of expression. The practical problem of implementing the right to be forgotten must also be taken into account, since, as a rule, deleting an article with personal information from the online media archive does not erase every online trace of personal information used. If not elsewhere, these will be available through the digitised archive of print media, which is generally provided by national libraries. ${ }^{53}$

In my view, given the fact that the right to be forgotten is a unitary and convention concept binding on all EU Member States, in order to ensure equal protection of individuals in its interpretation and implementation, it must be based on the same standards in all EU countries. In view of the fact that the CJEU court in the Google Spain case has not given specific and precise criteria and that the latter also do not derive from the General Regulation, it is my opinion that in case of weighing and resolving the conflict between the right to be forgotten and the freedom of media expression and information, it is necessary to proceed from the criteria established regarding the conflict between Article 8 and Article 10 of the ECHR that have already

\footnotetext{
${ }^{53}$ The process of digitization is underway at the National and University Library in Ljubljana, which means that publications from print media will be converted into digital form. This will allow everyone to e.g. by simply typing in the individual's first and last name, in a relatively easy and quick way, find all the printed articles relative to that person.
} 
been established by the ECtHR. ${ }^{54}$ These are, in particular, the criteria which the ECtHR, in addition to the matters mentioned above, have formulated in the case Von Hanover v. Germany ${ }^{55}$ and complement them in the case Axel Springer AD v. Germany, ${ }^{56}$ namely, what is the media contribution to the debate in the general interest, the visibility of the particular person and the topic of the newspaper article, the previous conduct of the person requesting erasure of the article, or erasure of the personal data contained therein, the content, format and consequences of the publication, the method and circumstances of obtaining the information and the severity of the sanction against the person who published the information. ${ }^{57}$ To this must be added the time aspect or the passage of time since the event covered by the media contribution as to whether the online access to some of the controversial content in question is limited (e.g. whether it is conditional on payment or subscription) and whether the erasure claimant has already requested that the URL be erased from search engines in order to make it difficult for them to track the content in question. It should also be emphasised that the requirement to anonymise an article or to change the contribution in respect of personal data, despite the fact that it is generally a more gentle measure than deleting an entire article, is not subject to criteria different or less stringent than those stated above. The ECtHR has, in the individualised information of a journalist's contribution, recognised an important element of journalistic work and thus of journalistic freedom. Therefore, it can be concluded that the request for erasure of articles or personal information contained in them which have been lawfully published and contain true information on which there is a public interest for being informed, would be as a rule unsuccessful. Thus, the right to be forgotten does not allow an individual to erase an article simply because one does not like to be the subject of media reporting or does not want it.

\section{Conclusion}

New technologies and the Internet are making a significant difference in the aspects and importance of individuals' privacy, which is gradually and slowly followed by the law. It is increasingly difficult to distinguish between information that is supposed to be public and that which is purely private (Frantziou, 2014: 776). The challenges

\footnotetext{
${ }^{54}$ Cf. The Debate The US Should Adopt the Right to Be Forgotten, Op. 45, available at https://www.intelligencesquaredus.org/debates/us-should-adopt-right-be-forgotten-online, last visited 2. 12 . 2018.

${ }^{55}$ No. $40660 / 08$ and 60641/08 from 7.2. 2012.

${ }^{56}$ No. 39954/08 from 7. 2. 2012.

${ }^{57}$ See Satakunnam Markkinapörssi Oy and Satamedia Oy v. Finland, no. 931/13 from 12. 7. 2015, and Kreča, 2017: 57.
} 
of protecting privacy on the Internet require a societal reflection on its importance and actual scope, and on how we, as a society, treat individuals' past mistakes. The Google Spain judgement and the General Regulation undoubtedly raise questions about the rights of the individual in the on-line environment. The right to be forgotten is not the right to a "perfect" past, but provides an individual with some control over one's personal information on the Internet under certain conditions. Its content and scope cannot be defined precisely, but its essential core is undoubtedly the individual's entitlement, based primarily on the right to respect one's private and family life, to request erasure of personal data or information on the basis of which an individual can be identified against any controller, whether it is a source website or an Internet search engine. The right to be forgotten is therefore a legal concept still at the beginning of its development, and case law will have to play a decisive role in shaping its content. It can be concluded that the right to be forgotten in relation to internet search engines is broader than it is the case of the relation to online media, where its passive aspect of the right to freedom of expression and information (which also protects the public's interest in accessing information, originating from online media archives) represents a significant limitation. Therefore, in the case of media contributions, the restriction of the exercise of the right of be forgotten is justified only by particularly strong, substantiated reasons, which, in my opinion, will be possible only rarely or in exceptional cases. In view of the fact that the CJEU in the Google Spain case has not given specific and precise criteria and that the latter also do not derive from the General Regulation, it is my opinion that in case of weighing and resolving the conflict between the right to be forgotten and the freedom of media expression and information, it is necessary to proceed from the criteria that have already been established by the ECtHR regarding the conflict between Article 8 and Article 10 of the ECHR. It should also be emphasised that the requirement to anonymise an article or any other modification of the article (e.g. removal of a photo from the article), despite the fact that it is a milder measure than erasing the entire article, is not subject to less stringent criteria than is the case with erasing it.

\section{References}

Bychawska-Siniarska, D. (2017) Protecting the right to freedom of expression under the European Convention on human Rights, A handbook for legal practitioners, (Council of Europe), https://rm.coe.int/handbook-freedom-of-expression-eng/1680732814 (visited 5. 12. 2018). 
van Calster, Geert., Apers, E., Gonzalez Arreaza, A. (2017) Not Just One, But Many 'Rights to Be Forgotten'. A Global Status Quo, https://ssrn.com/abstract=2938969 (visited 5. 12. 2018).

Copper, C. (2011) You've been Googled: what employers don't want to see in your online profile, The Guardian, https://www.theguardian.com/careers/careers-blog/googleonline-searches (visited 1. 12. 2018).

Floridi, L., Kauffman, S., Kolucka-Zuk, L., La Rue, F., Leutheusser-Schnarrenberger, S., Piñar, S. L., Valcke, P., Wales J. (2015) Report: The Advisory Council to Google on the Right to be Forgotten, https://archive.google.com/advisorycouncil/.../advisoryreport.pdf (visited 28. 11. 2018).

Frantziou, E. (2014) Further Developments in the Right to be Forgotten: the European Court of Justice's Judgement in Case C-131/12, Google Spain, SL, Google Inc v Agencia Espanola de Proteccion De Datos, Human rights Law Review, 14, pp. 761-777.

Guidelines on the implementation of the Court of Justice of the European Union judgment on "Google Spain and inc v. Agency of the Protección de Datos (AEPD) and Mario Costeja González "C-131/121 (2014) Article 29 Data protection working party, https://ec.europa.eu/justice/article-29/documentation/opinionrecommendation/index_en.htm, (visited on 1. 12. 2018).

Iglezakis, I. (2014) The Case of Case C-131/12: A Clear Victory for Data Protection or an Obstacle to the Internet?, https://ssrn.com/abstract=2472323 (visited on 1. 12. 2018).

Koops, B. (2011) Forgetting Footprints, Shunning Shadows. A Critical Analysis Of The "Right To Be Forgotten" In Big Data Practice, 8: 3 SCRIPTed 229, http://scripted.org/?p=43 (visited on 1. 12. 2018).

Kreča, M. (2017) Right to Forget, Master's Thesis (Faculty of Law, Ljubljana).

Kulk, S., Zuiderveen Borgesius, F. (2014) Google Spain v. González: Did the Court Forget About Freedom of Expression? European Journal of Risk Regulation 4. 9. 2014, https://ssrn.com/abstract=2491486 (visited on 1. 12. 2018).

Matthews, A. (2016) How The Italian Courts Used The Right To Be Forgotten To Put An Expiry Date On The News, The Guardian, https://www.theguardian.com/media/2016/sep/20/how-italian-courts-used-the-rightto-be-forgotten-to-put-an-expiry-date-on-news (visited 29. 11. 2018).

Montelero, A. (2013) The EU Proposal for a General Data Protection Regulation and the Roots of the Right to Be Forgotten, Computer Law \& Security Review 29(3), pp. 229-235.

Scorza G. (2016) A ruling by the Italian Supreme Court: News to "expire". Online archives would need to be deleted, L'ESPRESSO, http://espresso.repubblica.it/attualita/2016/07/01/news/a-ruling-by-the-italiansupreme-court-news-do-expire-online-archives-would-need-to- be-deleted-1.275720 (visited 28. 11.2018).

Spahiu, I. (2015) Between the right to know and the right to forget: looking beyond the Google case, European Journal of Law and Technology 6(2), pp.

Zittrain, J. (2014) Don't Force Google to Forget, The New York Times, https:/www.nytimes.com/2014/05/15/opinion/dont-force-google-to-forget.html (visited 3. 12. 2018)

Xue, M., Magno G., Cunha E., Alemida V., Ross, K.W. (2016) The Right to Be Forgotten in the Media, A Data Driven Study, De Gruyter Open, Proceedings on Privacy Enhancing Techologies, 4(1), pp. 389-402. 